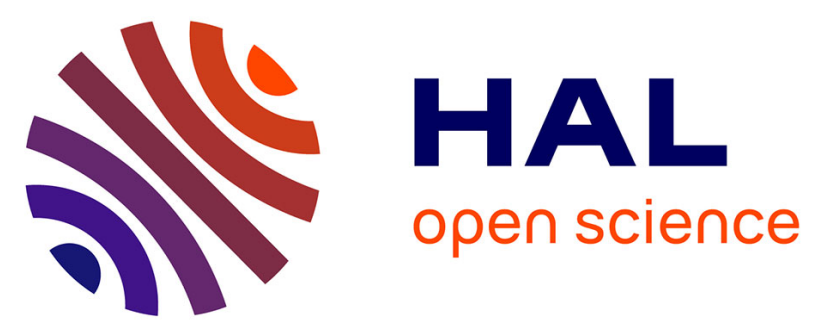

\title{
NMR determination of sorption isotherms in earlywood and latewood of Douglas fir. Identification of bound water components related to their local environment
}

Marie Bonnet, Denis Courtier-Murias, Pamela Françoise Faure, Stéphane Rodts, Sabine Caré

\section{To cite this version:}

Marie Bonnet, Denis Courtier-Murias, Pamela Françoise Faure, Stéphane Rodts, Sabine Caré. NMR determination of sorption isotherms in earlywood and latewood of Douglas fir. Identification of bound water components related to their local environment. Holzforschung, 2017, 71 (6), 10.1515/hf-20160152 . hal-01711369

\section{HAL Id: hal-01711369 \\ https://hal-enpc.archives-ouvertes.fr/hal-01711369}

Submitted on 24 Apr 2019

HAL is a multi-disciplinary open access archive for the deposit and dissemination of scientific research documents, whether they are published or not. The documents may come from teaching and research institutions in France or abroad, or from public or private research centers.
L'archive ouverte pluridisciplinaire HAL, est destinée au dépôt et à la diffusion de documents scientifiques de niveau recherche, publiés ou non, émanant des établissements d'enseignement et de recherche français ou étrangers, des laboratoires publics ou privés. 
Short title: Sorption isotherms observed by NMR

NMR determination of sorption isotherms in earlywood and latewood of Douglas fir. Identification of bound water components related to their local environment.

Marie BONNET ${ }^{1}$, Denis COURTIER-MURIAS ${ }^{1}$, Paméla FAURE ${ }^{1}$, Stéphane RODTS ${ }^{1}$, Sabine $\mathrm{CARE}^{1 *}$

${ }^{1}$ Laboratoire Navier, UMR 8205, École des Ponts, IFSTTAR, CNRS, UPE, Champs-surMarne, France

* Laboratoire Navier, Ecole des Ponts ParisTech, 6-8 avenue Blaise Pascal, Champs-surMarne, 77455 Marne-la-Vallée cedex 2, France

sabine.care@ifsttar.fr

Abstract: Earlywood (EW) and latewood (LW) have different hygromechanical behaviors, if subjected to relative humidity $(\mathrm{RH})$ variations. To understand this effect better, the adsorption mechanisms of EW and LW of Douglas fir were studied by $2 \mathrm{D}{ }^{1} \mathrm{H}$ NMR relaxometry under conditions of equilibrium moisture content (EMC) at $20^{\circ} \mathrm{C}$. Two bound water components were detected with relaxation times $T_{1}$ and $T_{2}$ indicating that they are located in distinct environments but these are similar in EW and LW. Sorption isotherms were calculated and analyzed based on the sorption model of Dent. A difference of sorption energy between the two water components is in agreement with their mobility difference observed on $\mathrm{T}_{1}-\mathrm{T}_{2}$ correlation spectra. Moreover, for the two bound water components, EW and LW exhibit different sorption isotherms at high RH. This may be attributed to a difference of adsorption capacity. Based on the macrofibril models provided by the literature, the following hypothesis is proposed: bound water components are located in lamellar and lenticular areas, both leading to possible deformations.

Keywords: 2D NMR relaxometry; adsorption, earlywood; hemicelluloses; latewood; macrofibril; 


\section{Introduction}

2 Wood structure is highly heterogeneous and hierarchically organized and therefore the

3 swelling behavior of wood in response to variations of relative humidity $(\mathrm{RH})$ is also

4 complex. The heterogeneity at the macroscopic scale is manifested in case of woods in the temperate zones as earlywood (EW) and latewood (LW), which also have distinct hygromechanical behaviors (Care et al. 2013; Almeida et al. 2014). The water affinity of the cell-wall components is provided by hydrophilic molecules with hydroxyl group concentrations in this decreasing order: cellulose $>$ hemicelluloses $>$ lignin. However, twothirds of cellulose hydroxyls are inaccessible to water, so that hemicelluloses are the most hydrophilic molecules in wood (Engelund et al. 2013). Sorption isotherms in materials have been classified in 6 types (Brunauer et al. 1940; Sing et al. 1985). They reflect sorption mechanisms, and their shape depends on physical and chemical interactions between water and solid substrate, and the number of accessible sorption sites. Many sorption isotherms exhibit hysteresis, thus adsorption and desorption isotherms can be differentiated. In this study, only adsorption is considered. The sorption isotherms of wood have a typical sigmoid shape and are commonly classified as type II. The BET theory (Brunauer et al. 1938) models wood sorption at low $\mathrm{RH}(<40 \%)$, assuming that primary water is strongly bonded to hydroxyl groups, and secondary water has thermodynamic properties identical to those of liquid water. Dent (1977) improved this model and proposed that the secondary water should have a binding energy higher than that of liquid water, and this approach shows a better fitting of the model at high RH. Usually, the Hailwood and Horrobin (1946) model is applied for wood, which considers sorption as solution phenomena with hydration and solution water components. The last isotherm models described in the literature are still a matter of debate (Willems 2015).

The localization of bound water requires knowledge of the supramolecular architecture of the cell-wall, which was improved in the last two decades (Donaldson 2007; Salmén and 
1 Burgert 2009; Salmén 2015). Macrofibrils are helically wound in the secondary wall.

2 However, they are not completely straight but slightly waved, and thus build intra-macrofibril

3 regions having a lenticular shape in the order of $10 \mathrm{~nm}$ (Boyd 1982; Gril 1988; Salmén 2015).

4 These lenticular areas are filled with a matrix of lignin and xylan. Furthermore, glucomannan

5 is present within macrofibrils and forms lamellar areas (Figure 1). Hypotheses were proposed

6 on the location of bound water in this structure (Gril 1988; Kulasinski et al. 2015) in order to

7 understand the effect on its hygromechanical behavior. For instance, Hunt (1990)

8 demonstrated that the longitudinal deformations and the hysteretic sorption behavior originate

9 from two different types of bound water located in different places.

${ }^{1} \mathrm{H}$ NMR relaxometry at low magnetic field (LF-NMR relaxometry) is well suited to water

11 identification and characterization in wood (Sharp et al. 1978: Menon et al. 1987; Araujo et

al. 1992; Araujo et al. 1994; Labbé et al. 2002; Almeida et al. 2007; Cox et al. 2010; Telkki et

al. 2013) and in pure cellulose or other cellulosic materials (Sasaki et al. 1960; Vittadini et al.

2001). This technique can discriminate and quantify protons in water or in organic molecules regarding their local environment, i.e. affinity with molecules they are bonded to, size of the bonded molecule, and pore size. Thus LF-NMR relaxometry is the method of choice for studies of water in porous media, such as wood, concrete, clay, etc. (Faure et al. 2005; Faure and Rodts 2008; Faure et al. 2012). An example of application in wood technology is the optimization of the process of thermal modification (Javed et al. 2015).

Sharp et al. (1978) studied first wood's moisture content (MC) by 1D NMR relaxometry.

Other studies quantified bound water and free water contents by spin-spin relaxation time $\left(\mathrm{T}_{2}\right)$ measurements (Menon et al. 1987; Araujo et al. 1992; Labbé et al. 2002). Some of these studies showed that liquid water may be present below the fiber saturation point (FSP), for instance in the case of hardwood species (Almeida et al. 2007). PSP was also determined through NMR measurements at various temperatures below and above the melting point of water (Telkki et al. 2013). In the hygroscopic range, Araujo et al. (1994) tried to separate 
1 hydration and solution water by $\mathrm{T}_{2}$ measurements, inspired by the sorption theory of

2 Hailwood and Horrobin (1946). However, the exchange time between these two water

3 components, which is linked to the diffusion distance of bound-water in cell-wall, turned out

4 to be too fast to enable their distinction. Cox et al. (2010) carried out 2D NMR relaxometry

5 experiments via $\mathrm{T}_{1}-\mathrm{T}_{2}$ correlation. Better splitting of water components permitted to detect

6 two types of bound water in wood cell-wall, which were attributed to confined water in small

7 clusters and to less mobile water, possibly at the origin of wood swelling. Thus the water

8 components cannot be differentiated in 1D experiments: in $\mathrm{T}_{2}$ spectra the relaxation times of

9 the signals are very close to each other, and in $T_{1}$ spectra, the peak corresponding to less

10 mobile water is superimposed by the solid wood peak.

11 It would be desirable to learn more about the two bound water components, especially to

12 find their location within the cell-wall structure and to evaluate their influence on the hygromechanical and sorption behaviors of wood. Hence, the aims of this study are to collect more information on the sorption mechanisms of bound water in wood and to compare EW and LW sorption behaviors. The expectation is that a better hypothesis can be presented concerning the location of bound water components in wood.

\section{Material and methods}

Sample preparation: Wood blocks were collected from a 58 years old Douglas fir tree (Pseudotsuga menziesii) from the coniferous forest of Ecouves (Orne, France). After natural drying in air, the material was stored at $19.9 \pm 0.2^{\circ} \mathrm{C}$ and $54 \pm 6 \% \mathrm{RH}$. Three earlywood and latewood (EW and LW) samples $\left(3 \times 10 \times 8 \mathrm{~mm}^{3}\right.$, RxTxL) were cut in the growth-ring no. 14 . It is located at the juvenile-mature transition and has a width of 6.1-mm and a LW proportion of 0.4. All the samples were taken side by side, in order to minimize the variability between samples of the same type (EW or LW). The total sampling volume was thus of $6 \times 24 \times 20$ $\mathrm{mm}^{3}$. Samples were cut with a diamond wire saw in the RT plane and with wood chisels for 
1 the RL and TL planes. A final polishing step was done with Silicon Carbide disks. The

2 density of the samples was determined by weighting and volume displacement measurements

3 with a resolution of $0.0001 \mathrm{~g}$ and $0.001 \mathrm{~mm}^{3}$, respectively. The average density at $12 \% \mathrm{MC}$

4 was $0.31 \mathrm{~g} \mathrm{~cm}^{-3}(\mathrm{EW})$ and $0.77 \mathrm{~g} \mathrm{~cm}^{-3}(\mathrm{LW})$. The presence of transition wood was not taken

5 into account.

6 All the samples had the same moisture history to avoid differences in this regard. Three

7 complete adsorption/desorption cycles were imposed to the samples. They were subjected

8 alternately for one week at $97 \% \mathrm{RH}$ (potassium sulfate) and for one week at $2 \% \mathrm{RH}$ (silica

9 gel) at $20^{\circ} \mathrm{C}$. The NMR adsorption experiment began at $2 \% \mathrm{RH}$. The studied material was

10 never oven-dried to avoid irreversible structural damages. The mass differences between

11 samples with $2 \% \mathrm{RH}$ and oven-dried samples (at $103^{\circ} \mathrm{C}$ ) were evaluated on parallel Douglas

12 fir samples. The equilibrium moisture content (EMC) at $2 \% \mathrm{RH}$ is about $2.5 \%$.

$$
\mathrm{EMC}_{\mathrm{x}}=\frac{\mathrm{m}_{\mathrm{x}}-\mathrm{m}_{0}}{\mathrm{~m}_{0}} \times 100
$$

where $\mathrm{EMC}_{\mathrm{x}}$ is at $\mathrm{x} \% \mathrm{RH}(\%), \mathrm{m}_{\mathrm{x}}$ the mass of the equilibrated sample $(\mathrm{g})$ and $\mathrm{m}_{0}$ the mass of the oven-dried sample (g).

Experimental protocol: NMR measurements were performed at 2, 23, 44, 65, 80, and 97\% RH. Each sample was equilibrated for one week. RH was controlled with silica gel (2\% RH) and saturated salt solutions $(\geq 23 \% \mathrm{RH})$ placed in desiccators at $19.9 \pm 0.2^{\circ} \mathrm{C}$ (Table 1$)$. Experimental conditions were recorded with thermo-hygrometers with a precision of $\pm 0.4^{\circ} \mathrm{C}$ and $\pm 2 \% \mathrm{RH}$, and the equilibrium state was checked daily by weighing. The average MC difference between two mass measurements at the equilibrium was $0.1 \%$.

NMR measurements at $20^{\circ} \mathrm{C}$ : NMR measurements were performed on a set of three EW and LW samples, respectively. The samples were inserted in a 18-mm diameter glass tube with the R direction oriented parallel to the tube axis (Figure 2), while the RH was controlled in each tube during the NMR experiments (Fourmentin 2015). To guarantee their equilibrium, 
1 samples were inserted the day before scanning. A BRUKER MINISPEC MQ20 spectrometer

2 was applied, which was operating at $0.5 \mathrm{~T}$, corresponding to a resonance frequency of 20

$3 \mathrm{MHz}$ for ${ }^{1} \mathrm{H}$ and enabling an analysis of samples with a maximum diameter of $18 \mathrm{~mm}$ and a

4 maximum height of $10 \mathrm{~mm}$. In a static magnetic field $\mathbf{B}_{\mathbf{0}}$, magnetic moments of ${ }^{1} \mathrm{H}$ nuclear

5 spins preferentially align with the $\mathbf{B}_{\mathbf{0}}$ direction. The average of these moments is called

6 macroscopic magnetization $\mathbf{M}$ and can be separated into a longitudinal component $\mathrm{M}_{\mathrm{L}}$ along

7 the $\mathbf{B}_{\mathbf{0}}$ direction, and a transversal component $\mathbf{M}_{\mathrm{T}}$. At the equilibrium state, $\mathbf{M}=\mathbf{M}_{\mathbf{0}}$ and is

8 oriented along the $\mathbf{B}_{\mathbf{0}}$ direction. The excitation of the magnetization $\mathbf{M}$ with a radiofrequency

9 (RF) pulse causes its disorientation and is followed by a precession-relaxation motion about

$10 \mathbf{B}_{\mathbf{0}}$ to come back to equilibrium. In simple samples, $\mathrm{M}_{\mathrm{L}}(\mathrm{t})$ and $\mathrm{M}_{\mathrm{T}}(\mathrm{t})$ relaxations obey first

11 order kinetics:

$$
\begin{gathered}
M_{L}(t)=M_{0}-A_{1} e^{-\frac{t}{T_{1}}} \\
\left|M_{T}(t)\right|=A_{2} e^{-\frac{t}{T_{2}}}
\end{gathered}
$$

where $A_{1}$ and $A_{2}$ depend on the initial conditions at $t=0 . T_{1}$ and $T_{2}$ are the spin-lattice (longitudinal) and spin-spin (transversal) relaxation times, respectively. They depend on molecular mobility of $\mathrm{H}$ atoms bearing molecules - in the present case water or solid wood molecules. They are also related to the strength of magnetic interactions between $\mathrm{H}$ spins and neighboring chemical species: the stronger the interactions, the shorter the relaxation times.

Relaxation kinetics of multicomponent systems - as humid wood material - appear as a sum of independent exponential processes. Spin-lattice and spin-spin kinetics are commonly measured with the inversion recovery (IR) (Hahn 1949) and Carr-Purcell-Meiboom-Gill (CPMG) sequences (Carr and Purcell 1954; Meiboom and Gill 1958), respectively. Inverse Laplace Transform (ILT) processing allows to some extent to resolve and quantify various components in the form of $1 \mathrm{D}$ spectra $v s . \mathrm{T}_{1}$ or $\mathrm{T}_{2}$ (Whittall and MaxKay 1989). Relaxation times of two components should differ by typically a factor of three for signal resolution, 
1 otherwise, the signals appear as one wide (merged) single peak (Brown 1989). Some other

2 biases of the method have also been pointed out by Faure and Rodts (2008).

$2 \mathrm{D} \mathrm{T}_{1}-\mathrm{T}_{2}$ correlation spectra (English et al. 1991) allow a better splitting of various components by classifying them according to pairs of $T_{1}$ and $T_{2}$ values. This technique was successful in identifying two bound water components in wood (Cox el al. 2010) and allowed a clear improvement over 1D experiments. Measurements consist of coupling IR and CPMG sequences as presented in Figure 3. Sequence is repeated for different values of $t_{\mathrm{m}}$ delay, for which a signal is recorded at the top of each echo generated in series, as a function of both $t_{m}$ and echo index $n$. Signal from a sample component with identified $\mathrm{T}_{1}$ and $\mathrm{T}_{2}$ values and equilibrium magnetization - considered as the 'weight' of the component $\mathrm{W}$ reads:

$$
S\left(t_{m}, n T E\right)=W\left(1-2 e^{-\frac{t_{m}}{T_{1}}}\right) \cdot e^{-\frac{n T E}{T_{2}}}
$$

11 Overall signal of a multi-component sample is regarded as the sum of such elementary contributions. 2D spectra aiming at retrieving components as a function of $\mathrm{T}_{1}$ and $\mathrm{T}_{2}$ are computed through a 2D Inverse Laplace Transform (ILT), for which a practical algorithm was proposed in recent years (Song et al. 2002). The volume under each peak of the 2D spectra is proportional to an amount of $\mathrm{H}$ atoms. The $\mathrm{T}_{1}$ and $\mathrm{T}_{2}$ values of each peak are determined by means of the coordinates of their respective maxima. 2D spectra also give unambiguous access to $T_{1} / T_{2}$ ratios. The latter is characteristic of $H$ atoms mobility and confinement and greatly helps spectrum interpretation. Values close to 1, 2-6, and over 10 correspond to (i) unconfined water, (ii) mobile water at free or adsorbed state and (iii) bonded immobile water molecule and solid macromolecules, respectively. Ratios lower than one are physically not permitted (Abragam 1961).

In this work, delay $t_{m}$ of the IR sequence was increased in 60 steps as a geometric series (i.e. following a regular sampling on a logarithmic scale) from 0.01 to $1000 \mathrm{~ms}$. CPMG echo train comprised 200 successive echoes with an echo time $\mathrm{TE}=60 \mu \mathrm{s}$, among which 50 echoes 
1 were recorded for measurement times nxTE, following approximately a geometric series from

$260 \mu$ s to $12 \mathrm{~ms}$. To increase the signal-to-noise ratio $(\mathrm{S} / \mathrm{N})$, the $\mathrm{T}_{1}-\mathrm{T}_{2}$ sequence was repeated

3192 times for LW and 384 times for EW due to its lower density generating less signal.

4 Repetition delay TR was chosen higher than five times the highest $\mathrm{T}_{1}$ value to ensure

5 complete equilibrium recovery between successive sequences, and was finally set to $\mathrm{TR}=1 \mathrm{~s}$

6 to also avoid excessive RF power deposition of the CPMG part of the sequence on the sample

7 and keep sample temperature constant.

8 The free induction decay (FID) sequence was also performed to validate the quantitative

9 NMR measurements as FID detects the quasi-totality of $\mathrm{H}$ atoms by measuring the signal just

10 after the emission of one single RF pulse (with a low dead time of $8 \mu \mathrm{s}$ ). The FID signal

11 intensity is thus proportional to the number of $\mathrm{H}$ atoms in the studied material. The $\mathrm{H}$ atoms

12 in wood supposed to be linearly evolved with the mass of water in the sample, an assumption

13 which could be verified (Figure 4). Normalization choices in the 2D-ILT software lead to a

14 proportional relation between peak volume of the 2D spectra and FID intensity by a constant

15 multiplicative factor.

16 2D-ILT data processing: Of particular importance in this study is the calculation of $\mathrm{T}_{1}-\mathrm{T}_{2}$ correlation spectra from NMR data, which was performed based on a homemade software essentially reproducing the 2D-ILT algorithm of Song et al. (2002). Spectra are described as a matrix of $a_{i, j}$ values on a fixed, predefined grid of relaxation times $T_{1 i}$ and $T_{2 j}$ regularly spaced on a logarithmic axis (typically 100 values per axis) and spanning the desired area to

21 be observed. They are determined by a least square fit to the data with non-negative constraint and Tikhonov regularization:

$$
\left\{a_{i, j}\right\}=\operatorname{ArgMin}_{a_{i, j} \geq 0} \sum_{n, m}\left(s\left(t_{m}, n T E\right)-\sum_{i, j} a_{i, j} K_{i, j, n, m}\right)^{2}+\lambda \sum_{i, j} a_{i, j}{ }^{2}
$$




$$
\text { with } K_{i, j, n, m}=\left(1-2 e^{-\frac{t_{m}}{T_{1 i}}}\right) \cdot e^{-\frac{n T E}{T_{2 j}}}
$$

1 where $\lambda$ is a positive parsimony parameter, which ensures regularity of the spectrum. This is

2 necessary because of the not perfectly conditioned nature of unconstrained least square fit.

3 Spectrum positivity seems to be a reasonable physical assumption in many cases, but it is

4 actually a requirement of the algorithm itself. This point was criticized in the past because

5 some specific samples may also exhibit negative spectral components (Rodts and Bytchenkoff

6 2010, 2011). Despite some attempts, no fully convincing alternative for processing has been

7 proposed up to now. To make the optimization problem (5) tractable on a standard PC, the

8 original algorithm replaces kernel operator K by a SVD approximation (Singular Value

9 Decomposition, made possible by the product structure of K) truncated to highest singular

10 values so as to retain a condition number of 1000 . This is a kind of data compression, which

11 reduces by orders of magnitude the number of parameters to handle in calculations. The non-

12 negative truncated problem is finally solved by the BRD algorithm (Butler et al. 1981). This

13 algorithm not only calculates the spectrum for a given $\lambda$ value, but also automatically

14 optimizes $\lambda$ value according to the noise level on NMR data.

15 In this work, the algorithm had to be corrected because of some imperfections. The condition number for SVD approximation was increased to $10^{6}$, as it was observed that lower values are too rough and produce a significant bias on calculated spectra. Also, BRD algorithm was used only to calculate spectra at fixed $\lambda$ value, because $\lambda$ optimization failed to converge in some cases. The more robust and traditional S-curve approach was used instead, consisting in choosing the highest $\lambda$, which still permits fitting quality (Whittall and MacKay 21 1989).

22 Error assessments: (i) The uncertainty due to eventual variations of MC during NMR experiments has been quantified by weighing the samples before and after each NMR 
1 wood type was evaluated by weighting. It was verified that the sampling protocol leads to

2 only a very small variability between the three samples. (iii) The stability of the NMR

3 apparatus was also taken into account, as the totality of the experiment lasted several weeks.

4 Systematic calibrations with a standard reference sample were performed and the NMR coil

5 was additionally detuned to make its sensitivity independent on sample composition. (iv)

6 Some bias linked to the 2D ILT data processing may appear and affect the measured values.

7 The stability of this data processing was analyzed by adding white noise on a model signal

8 that is close to the experimental data, as proposed by Cox et al. (2010).

9 The error bars of the MCs have been calculated based on the above mentioned

10 uncertainties. The average uncertainty for the whole hygroscopic range is $\pm 0.8 \% \mathrm{MC}$.

11 Regarding $\mathrm{T}_{1}$ and $\mathrm{T}_{2}$ values, only the noise effect was taken into account. However, if known 12 problems of 1D-ILT are extrapolated to the 2D case (Faure and Rodts 2008), an additional 13 bias can occur owing to the 'mathematical' interaction between neighboring peaks: $\mathrm{T}_{1}$ and $\mathrm{T}_{2}$

14 can easily be over- or underestimated by a factor of 1.5 without any particular physical

15 meaning. Therefore, only stronger effects should be sought for.

16 Analysis of sorption isotherms: The analysis is based on the Dent (1977) theory, where the

17 evolution of adsorbed water quantity reads as a function of RH:

$$
\frac{y}{y_{m}}=\frac{b_{0} x}{(1-b x)\left(1-b x+b_{0} x\right)}
$$

18 where $\mathrm{y}$ is the $\mathrm{MC}$ (in $\mathrm{g} \mathrm{g}^{-1}$ of dry material), $\mathrm{ym}_{\mathrm{m}}$ the theoretical MC of the primary water when

19 it reaches saturation (in $\mathrm{g} \mathrm{g}^{-1}$ of dry material) and $\mathrm{x}$ the $\mathrm{RH}(-)$. The two dimensionless

20 constants $b_{0}$ and $b$ are linked to the variation of Gibbs energy of water from the liquid state to

21 the adsorbed state, which are $\Delta \mathrm{G}_{0}$ and $\Delta \mathrm{G}$ (in $\mathrm{J} . \mathrm{mol}^{-1}$ ), respectively:

$$
\begin{aligned}
& \text { Primary water: } \Delta \mathrm{G}_{0}=-\mathrm{RT} \ln \left(\mathrm{b}_{0}\right) \\
& \text { Secondary water: } \Delta \mathrm{G}=-\mathrm{RT} \ln (\mathrm{b})
\end{aligned}
$$


1 where $\mathrm{R}=8.314 \mathrm{~J} \mathrm{~mol}^{-1} \mathrm{~K}^{-1}$ is the gas constant and $\mathrm{T}$ is the temperature in ${ }^{\circ} \mathrm{K}$. The $\mathrm{RH}$ for

2 which the secondary water begins to be adsorbed (i.e. $\mathrm{y} / \mathrm{y}_{\mathrm{m}}=1$ ) is denoted $\mathrm{x}_{\mathrm{m}}$. These physical

3 parameters are obtained by a fit of the model to the data by the least square method.

$5 \quad$ Results and discussion

6 Validation of NMR measurements: Figure 4a shows the evolution of the first data point

7 intensity of recorded signal as a function of the mass of adsorbed water determined by

8 weighing. At $2 \% \mathrm{RH}$, signal mainly corresponds to $\mathrm{H}$ atoms of wood molecules. The ratio of

9 FID signal LW/EW at 2\% RH (2.9) is quite similar to the ratio of the dry densities (2.6). A linear dependence is found between signal increase and water adsorption with an identical

11 slope for EW and LW.

$\mathbf{T}_{1}-\mathbf{T}_{\mathbf{2}}$ correlation spectra: In the whole hygroscopic range, five main peaks appear on $\mathrm{T}_{1}-\mathrm{T}_{2}$ correlation spectra for both EW and LW samples as exhibited in Figure 5 corresponding to $65 \% \mathrm{RH}$. The evolution of the spectra with $\mathrm{RH}$ is shown in Figure 6, where low signal values were removed to highlight the peaks B and C.

Peak $\mathrm{D}$ is identified as a signal of $\mathrm{H}$ atoms belonging to wood molecules as its long $\mathrm{T}_{1}$ and short $\mathrm{T}_{2}$ (with $\mathrm{T}_{1} / \mathrm{T}_{2} \approx 2000$ ) are the signature of relatively rigid molecules with little mobility (Cox et al. 2010). Moreover, its volume remains constant despite of RH variations $(3.8 \pm 0.1$ and $10.0 \pm 0.6$ (FID units) for EW and LW respectively).

$$
\text { Peaks } \mathrm{B} \text { and } \mathrm{C} \text { are attributed to bound water. Indeed, their } \mathrm{T}_{1} / \mathrm{T}_{2} \text { ratio is much lower than }
$$
that of peak D suggesting a greater mobility. Also, the sum of peaks B and C volumes linearly increases with the mass of adsorbed water determined by weighing (Figure $4 \mathrm{~b}$ ). The position of peak B suggests that it could be an exchange peak between $C$ and $D$, thus forming an exchange square of the B-kind (Bytchenkoff and Rodts 2011). However, off-diagonal peaks in an exchange $T_{2}-T_{2}$ spectrum were not observed in such experiments (Cox et al. 2010). Therefore, peaks B and C correspond to bound water located in two specific and distinct 
1 water reservoirs. Compared to peak $\mathrm{C}$, peak $\mathrm{B}$ has a higher $\mathrm{T}_{1} / \mathrm{T}_{2}$ ratio indicating more

2 restricted molecular motions: water molecules of peak B have stronger interactions with wood

3 molecules as also demonstrated by Cox et al. (2010).

4 Finally, peaks A' and A', are assigned to liquid water which could be present in large 5 pores below the FSP (Almeida et al. 2007) as they have high $T_{1}$ and $T_{2}$ values and a $T_{1} / T_{2}$

6 ratio ranging between 1 and 5 . The position of peak A" slightly above the $T_{1}=T_{2}$ diagonal is

7 probably a location error due to its very low intensity.

8 Evolution of $\mathbf{T}_{\mathbf{1}}$ and $\mathbf{T}_{\mathbf{2}}$ values with RH: As observed on Figure 7, EW and LW exhibit very

9 close $\mathrm{T}_{1}$ and $\mathrm{T}_{2}$ values evolutions with $\mathrm{RH}$ for both peaks B and C. Although EW and LW have not the same proportion of chemical constituents in their cell-walls (Meier and Wilkie 11 1959), this result indicates that the nature of adsorption sites is quite similar in EW and LW, i.e. they share many structural and chemical similarities at the nanometer scale. Furthermore, as $\mathrm{RH}$ increases $\mathrm{T}_{1} / \mathrm{T}_{2}$ ratio decreases continuously for both peaks $\mathrm{B}$ and $\mathrm{C}$ (Figure 7d): it is reduced by a factor of 46 and 8 respectively, showing that both types of water gain mobility as the number of adsorbed molecules increases. A thorough analysis of independent evolution of $\mathrm{T}_{1}$ and $\mathrm{T}_{2}$ is more delicate, but the increasing trend with $\mathrm{RH}$ of the $\mathrm{T}_{2}$ values supports the idea of mobility increment. It is not clear, however, at this stage whether this mobility concerns water molecules themselves, or the - possibly mobile structures bearing adsorption sites. As already pointed out by Cox et al. (2010), adsorption energy on sorption sites is also likely to change if additional water molecules adsorb at a same 21 place. Moreover, a softening of the structure at high RH may appear (Engelund et al. 2013). Finally, the $T_{1} / T_{2}$ ratio does not seem to stabilize at high $\mathrm{RH}$ contrary to what is usually observed in rigid systems such as porous silica (D'Orazio et al. 1989; D'Orazio et al. 1990; Porion et al. 1998). This suggests that water molecules appearing at high RH may still 
1 the interpretation of Cox et al. (2010) concerning their attribution of C-water to small water

2 clusters.

3 Sorption isotherms: The sorption isotherms are calculated using the proportional coefficient

$4 \alpha$ (equal to $152 \pm 6 \mathrm{~g}^{-1}$ ) of the linear trend observed in Figure 4, which enables to convert

5 NMR signal quantity into MC (under the same experimental conditions). Thus, for calculation

6 of sorption isotherms the following equation is used:

$$
\mathrm{q}_{\mathrm{x} \%}-\mathrm{q}_{2 \%}=\alpha\left(\mathrm{w}_{\mathrm{x} \%}-\mathrm{w}_{2 \%}\right)
$$

7 where $\mathrm{q}_{\mathrm{x} \%}$ and $\mathrm{q}_{2 \%}$ (a.u.) are the NMR signal quantities at the $\mathrm{RH} \times \%$ and $2 \%$ (equilibrium state) and $\mathrm{w}_{\mathrm{X} \%}$ and $\mathrm{w}_{2 \%}(\mathrm{~g})$ are the masses of water in wood equilibrated at the $\mathrm{RH} \mathrm{x} \%$ and $2 \%$. Because the NMR signal quantities for B- and C-water can be measured separately by $2 \mathrm{D}$ NMR experiments and $\mathrm{w}_{2} \%$ is known, Eq. 9 can be used to calculate $\mathrm{w}_{\mathrm{x} \%}$ at various $\mathrm{RH}$ values and thus to obtain individual sorption isotherms for B- and C-water. Note that this equation is also suitable to determine the MC related to the dry state by extrapolation.

8. The two curves are quite similar confirming the literature results (Hill et al. 2015), and exhibit the common shape of the wood sorption isotherm (type II).

The individual sorption isotherms of B- and C-water can also be determined (Figure 9). Bwater has a sorption isotherm of type II, in the whole investigated $\mathrm{RH}$ range for LW and until $65 \% \mathrm{RH}$ for $\mathrm{EW}$, while C-water has a sorption isotherm of type III. Thus, the sigmoid shape of the sorption isotherm of wood emerges from the combination of two distinct sorption processes, which occur in their respective locations. Sorption isotherms are quantified according to the theory of Dent (1977): free energies of primary and secondary waters are calculated for each experimental sorption isotherm (Table 2). Note that the obtained values are of the same order of magnitude as those of the literature (Skaar 1988). First, secondary water is weakly bound compared to primary water as $\Delta \mathrm{G}_{0}<\Delta \mathrm{G}$. Moreover, $\Delta \mathrm{G}>0$ so that 
1 the adsorption of secondary water is partly restricted (compared to the condensation of bulk

2 water) by some unfavorable energetic conditions, which are not yet understood. Also, Gibbs energy values support the view that B-water has a stronger interaction strength than C-water usual interpretation that type II isotherm corresponds to adsorption with higher attractive forces between wood and water molecules than type III isotherm (Brunauer et al. 1940; Dent 1977). This is supported as well by the $\mathrm{x}_{\mathrm{m}}$ value, indicating an earlier beginning of the secondary water adsorption in the B-environment than in the C-environment.

Furthermore, EW and LW exhibit almost identical sorption isotherms until 65\% RH.

However, at higher RH, B-water reaches saturation in EW, whereas in LW, it is still increasing in a significant way. The inverse behavior is observed for C-water, the content of which increases less in LW than in EW at high RH. The current NMR data do not allow explaining the sorption isotherms differences between EW and LW. However, a hypothesis in accordance with the positivity of $\Delta \mathrm{G}$ is proposed: the saturation of a sorption isotherm could be due to a limited adsorption capacity, for instance because of insufficient space or because of a limited softening of the cell-wall structure at high $\mathrm{RH}$, which influences the accommodation of water molecules (Engelund et al. 2013). In the case of B-water in EW, the $\mathrm{T}_{2}$ value continues to increase with $\mathrm{RH}$ although no more $\mathrm{B}$-water is adsorbed. This may indicate that - although B and C are regarded as two distinct reservoirs, which do not significantly exchange water at the time scale of an NMR experiment - , they could nevertheless be located fairly close one to each other to enable interactions, the exact nature of which remains unclear at this stage.

Hypothesis on water molecules environments: The hygromechanical behavior of wood could be affected by two types of water located in different areas of the wood structure (Gril 1988; Hunt 1990). The current NMR results show that there are two bound water components, 
1 degree of interaction. Yet, two main areas of the wood structure, which are accessible to

2 water, but which have different sorption environments, stand out: the lenticular and the

3 lamellar areas (Figure 1). Their proximity within a few nanometers should be enough to

4 enable some interactions, but avoid exchanges during the NMR experiment time, provided the

5 case that the typical residence time of water molecules in each area is long enough. The latter

6 hypothesis should be checked in further studies by means of specific experiments. Moreover,

7 their structural and chemical properties are very different, so that they should have distinct

$8 \quad$ NMR relaxation properties.

9 Lamellar areas are more arranged and hydrophilic, enabling stronger interactions with

10 water than lenticular areas. Yet, B-water is more strongly bound to wood molecules so that it

11 should be located in lamellar areas and C-water in lenticular areas.

12 Note that for a given environment, NMR relaxometry cannot identify the nature of each water molecule because of the various sorption sites in close proximity. Therefore, adsorption

14 sites in B-and C-environment may be a mixing of sorption sites of different nature.

According to the proposed hypothesis, water molecules in lamellar areas could be adsorbed on glucomannan, at the interface with microfibrils, and in amorphous areas of microfibrils. In

17 lenticular areas, they could be adsorbed on sorption sites of xylan, lignin, and glucomannan found at the interface with macrofibrils. This hypothesis is an alternative to that of Cox et al. (2010), who attributed B-water to adsorbed water and C-water to small water clusters, which does not contribute to moisture-induced deformations. In coherence with the NMR results and

21 the structure of the cell-wall, both types of water should interact with wood molecules and 22 induce deformations.

\section{Conclusions}

$252 \mathrm{D}{ }^{1} \mathrm{H}$ NMR relaxometry in the whole hygroscopic range affords new insights of moisture 26 sorption in EW and LW. By means of $\mathrm{T}_{1}-\mathrm{T}_{2}$ correlation spectra, bound water was separated 
1 into two components, which have not the same mobility and are located in distinct

2 environments. Their respective sorption isotherms were determined and analyzed based on the

3 Dent theory, which revealed unequal interactions strengths with wood molecules. Both bound

4 water components were observed in EW and LW and exhibited similar $\mathrm{T}_{1}$ and $\mathrm{T}_{2}$ values and

5 dependence on RH, suggesting that bound water in EW and LW is situated in similar

6 environments. However, sorption isotherms of bound water components turned out to be

7 different between EW and LW at high RH, possibly due to a difference of sorption capacity.

8 Further experiments would be necessary to better understand these differences. Furthermore,

experimental data and sorption isotherms analysis helped to assign the two bound water

components at the macrofibril scale: the strongly bound water would be located in lamellar

areas and the weakly bound water in lenticular areas. This hypothetic model gives

perspectives for the understanding on the deformations induced by moisture sorption and to

compare their effect on the hygromechanical behavior of EW and LW.

Acknowledgments: The Douglas supply by INRA Nancy (France) is acknowledged, in the insightful comments of reviewers from Holzforshung.

\section{References}

Abragam, A. The Principles of Nuclear Magnetism. Clarendon Press, Oxford, 1961.

Almeida, G., Gagné, S., Hernandez, R.E. (2007) A NMR study of water distribution in hardwoods at several equilibrium moisture contents. Wood Sci. Technol. 41:293-307.

Almeida, G., Huber, F., Perré, P. (2014) Free shrinkage of wood determined at the cellular level using an environmental Scanning Electron Microscope. Maderas-Cienc. Tecnol. 16:187-198.

Araujo, C.D., Avramidis, S., MacKay, A.L. (1994) Behaviour of solid wood and bound water as a function of moisture content: a proton magnetic resonance study. Holzforschung 48:69-74.

Araujo, C.D., MacKay, A.L., Hailey, J.R.T., Whittall, K.P. (1992) Proton magnetic resonance techniques for characterization of water in wood: application to white spruce. Wood Sci. Technol. 26:101-113.

Boyd, J.D. (1982) An anatomical explanation for visco-elastic and mechano-sorptive creep in wood, and effects of loading rate on stregth. In: New Perspectives in Wood Anatomy, Eds. Martinus Nijhoff/Dr. W. Junk Publishers, La Hague. pp. 171-222.

Brown, R. (1989) Information available and unavailable from multiexponential relaxation data. J. Magn. Reson. 82:539-561. 
Brunauer, S., Deming, L.S., Deming, W.E., Teller, E. (1940) On the theory of the Van der Waals adsorption of gases. J. Am. Chem. Soc. 62:1723-1732.

Brunauer, S., Emmett, P., Teller, E. (1938) Adsorption of gases in multimolecular layers. J. Am. Chem. Soc. 60:309-319.

Butler, J., Reeds, J., Dawson, S. (1981) Estimating solutions of first kind integral equations with nonnegative constraints and optimal smoothing. SIAM J. Numer. Anal. 18:381397.

Bytchenkoff, D., Rodts, S. (2011) Structure of the two-dimensional relaxation spectra seen within the eigenmode perturbation theory and the two-site exchange model. J. Magn. Reson. 208:4-19.

Care, S., Lenoir, N., Bertrand, F., Bornert, M. (2013) Microstructural and multiscale characterization of wood subjected to humidity by X-ray microtomography and Magnetic Resonance Imaging. ICTMS Conference, Ghent, Belgium, 4 p.

Carr, H., Purcell, E. (1954) Effects of diffusion on free precession in nuclear magnetic resonance experiments. Phys. Rev. 94:630-638.

Cox, J., McDonald, P.J., Gardiner, B.A. (2010) A study of water exchange in wood by means of 2D NMR relaxation correlation and exchange. Holzforschung 64:259-266.

Dent, R. (1977) A multilayer theory for gas sorption. Part I: sorption of a single gas. Text. Res. J. 47:145-152.

Donaldson, L. (2007) Cellulose microfibril aggregates and their size variation with cell wall type. Wood Sci. Technol. 41:443-460.

D'Orazio, F., Bhattacharia, S., Halperin, W. (1989) Enhanced self-diffusion of water in restricted geometry. Phys. Rev. Lett., 63:43-46.

D'Orazio, F., Bhattacharia, S., Halperin, W.P., Eguchi, K., Mizusaki, T. (1990) Molecular diffusion and nuclear-magnetic-resonance relaxation of water in unsaturated porous silica glass. Phys. Rev. B, 42:9810-9818.

Engelund, E.T., Thygesen, L.G., Svensson, S., Hill, C.A.S. (2013) A critical discussion of the physics of wood-water interactions. Wood Sci. Technol. 47:141-161.

English, A., Whittall, K., Joy, M., Henkelman, R. (1991) Quantitative two-dimensional time correlation relaxometry. Magn. Reson. Med. 22:425-434.

Faure, P., Caré, S., Po, C., Rodts, S. (2005) An MRI-SPI and NMR relaxation study of drying-hydration coupling effect on microstructure of cement-based materials at early age. Magn. Reson. Imaging 23:311-314.

Faure, P., Peter, U., Lesueur, D., Coussot, P. (2012) Water transfers within Hemp Lime Concrete followed by NMR. Cement Concrete Res. 42:1468-1474.

Faure, P., Rodts, S. (2008) Proton NMR relaxation as a probe for setting cement pastes. Magn. Reson. Imaging 26:1183-1196.

Fourmentin, M. (2015) Impact de la répartition et des transferts d'eau sur les propriétés des matériaux de construction à base de chaux formulées. PhD thesis: Université Paris-Est, France.

Greenspan, L. (1977) Humidity fixed points of binary saturated aqueous solutions. J. Res. Nbs. A Phys. Ch. 81A:89-96.

Gril, J. (1988) Une modélisation du comportement hydro-rhéologique du bois à partir de sa microstructure. PhD thesis: Université Pierre et Marie Curie (Paris 6), France.

Hahn, E. (1949) An accurate nuclear magnetic resonance method for measuring spin-lattice relaxation times. Phys. Rev. 76:145-147.

Hailwood, A., Horrobin, S. (1946) Absorption of water by polymers. Analysis in terms of a simple model. Trans. Far. Soc. 42B:84-102.

Hill, C., Ramsay, J., Gardiner, B. (2015) Variability in water vapour sorption isotherm in Japanese Larch (Larix kaempferi Lamb.) - earlywood and latewood influences. Int. Wood Prod. J. 6:53-59. 
Hunt, D.G. (1990) Longitudinal shrinkage-moisture relations in softwood. J. Mater. Sci. 25:3671-3676.

Javed, M.A., Kekkonen, P.M., Ahola, S., Telkki, V.-V. (2015) Magnetic resonance imaging study of water absorption in thermally modified pine wood. Holzforschung, 69(7):899907.

Kulasinski, K., Guyer, R., Derome, D., Carmeliet, J. (2015) Water adsorption in wood microfibril-hemicellulose system: role of the crystalline-amorphous surface. Biomacromolecules 16:2972-2978.

Labbé, N., De Jéso, B., Lartigue, J.-C., Daudé, G., Pétraud, M., Ratier, M. (2002) Moisture content and extractive materials in Maritime Pine wood by low field ${ }^{1} \mathrm{H}$ NMR. Holzforschung 56:25-31.

Meiboom, S., Gill, D. (1958) Modified spin-echo method for measuring nuclear relaxation times. Rev. Sci. Instrum. 29:688-691.

Meier, H., Wilkie, K.C.B. (1959) The distribution of polysaccharides in the cell-wall of tracheids of Pine (Pinus silvestris L.). Holzforschung 13:177-182.

Menon, R. et al. (1987) An NMR determination of the physiological water distribution in wood during drying. J. Appl. Polym. Sci. 33:1141-1155.

Porion, P., Faugère, A.M., Levitz, P.E., VanDamme, H., Raoof, A., Guilbaud, J.-P., Chevoir, F. (1998) A NMR investigation of adsorption/desorption hysteresis in porous silica gels. Magn. Reson. Imaging 16:679-682.

Rodts, S., Bytchenkoff, D. (2010) Structural properties of 2D NMR relaxation spectra of diffusive systems. J. Magn. Reson. 205:315-318.

Salmén, L., Burgert I. (2009) Cell wall features with regard to mechanical performance. A review. Holzforschung 63:121-129.

Salmén, L. (2015) Wood morphology and properties from molecular perspectives. Ann. For. Sci. 72:679-684.

Sasaki, M., Kawai, T., Hirai, A., Hashi, T., Odajima, A. (1960) A study of sorbed water on cellulose by pulsed NMR technique. J. Phys. Soc. Jpn. 15:1652-1657.

Sharp, A., Riggin, M., Kaiser, R. (1978) Determination of moisture content of wood by pulsed nuclear magnetic resonance. Wood Fiber Sci., 10:74-81.

Sing, K.S.W., Everett, D.H., Haul, R.A.W., Moscou, L., Pierotti, R.A., Rouquerol, J., Siemeneawska, T. (1985) Reporting physisorption data for gas/solid systems with special reference to the determination of surface area and porosity. Pure Appl. Chem. 57:603-619.

Skaar, C. Wood-water relations. Springer-Verlag, Berlin, 1988.

Song, Y.Q., Venkataramanan, L., Hürlimann, M.D., Flaum, M., Frulla, P., Straley, C. (2002) T1-T2 correlation spectra obtained using a fast two-dimensional Laplace inversion. J. Magn. Reson. 154:261-268.

Telkki, V.-V., Yliniemi, M., Jokisaari, J. (2013) Moisture in softwoods: fiber saturation point, hydroxyl site content, and the amount of micropores as determined from NMR relaxation time distributions. Holzforschung 67(3):291-300.

Vittadini, E., Dickinson, L., Chinachoti, P. (2001) 1H and 2H NMR mobility in cellulose. Carbohyd. Polym. 46:49-57.

Whittall, K., MacKay, A. (1989) Quantitative interpretation of NMR relaxation data. J. Magn. Reson. 84:134-152.

Willems, W. (2015) A critical review of the multilayer sorption models and comparison with the sorption site occupancy (SSO) model for wood moisture sorption isotherm analysis. Holzforschung 69:67-75.

Winston, P., Bates, D. (1960) Saturated solutions for the control of humidity in biological research. Ecology 41:232-237 


\section{Tables}

2 Table 1 Chemicals to control RH $\left(20^{\circ} \mathrm{C}, \mathrm{P}_{\mathrm{atm}}\right)$ (Winston and Bates 1960; Greenspan 1977).

\begin{tabular}{|c|c|}
\hline $\begin{array}{l}\mathrm{RH} \\
(\%)\end{array}$ & Chemicals \\
\hline 2 & Silica gel \\
\hline 23 & $\begin{array}{l}\text { Potassium acetate } \\
\left(\mathrm{C}_{2} \mathrm{H}_{3} \mathrm{KO}_{2}\right)\end{array}$ \\
\hline 44 & $\begin{array}{l}\text { Potassium carbonate } \\
\left(\mathrm{K}_{2} \mathrm{CO}_{3}\right)\end{array}$ \\
\hline 65 & Sodium nitrite $\left(\mathrm{NaNO}_{2}\right)$ \\
\hline 80 & $\begin{array}{l}\text { Ammonium sulfate } \\
\left(\mathrm{H}_{8} \mathrm{~N}_{2} \mathrm{O}_{4} \mathrm{~S}\right)\end{array}$ \\
\hline 97 & Potassium sulfate $\left(\mathrm{K}_{2} \mathrm{SO}_{4}\right)$ \\
\hline
\end{tabular}

3

4 Table 2 Parameters of sorption isotherms as fitted based on the Dent theory.

\begin{tabular}{|c|c|c|c|c|c|}
\hline & & $\begin{array}{l}X_{m} \\
(\%)\end{array}$ & $\begin{array}{l}y_{m} \\
(\%)\end{array}$ & $\begin{array}{c}\Delta \mathrm{G}_{0} \\
\left(\mathrm{~kJ} \mathrm{~mol}^{-1}\right.\end{array}$ & $\begin{array}{c}\Delta \mathrm{G} \\
\left(\mathrm{kJ} \mathrm{mol}^{-1}\right)\end{array}$ \\
\hline \multirow{2}{*}{$\begin{array}{l}\mathrm{B} \\
\text { water }\end{array}$} & EW & 20.50 & 4.23 & -8.10 & 1.06 \\
\hline & LW & 18.61 & 3.97 & -8.25 & 0.76 \\
\hline \multirow{2}{*}{$\begin{array}{l}\mathrm{C} \\
\text { water }\end{array}$} & $\mathrm{EW}$ & 44.84 & 2.82 & -2.60 & 0.70 \\
\hline & LW & 49.94 & 2.90 & -2.34 & 0.96 \\
\hline
\end{tabular}

5 


\section{Figures}

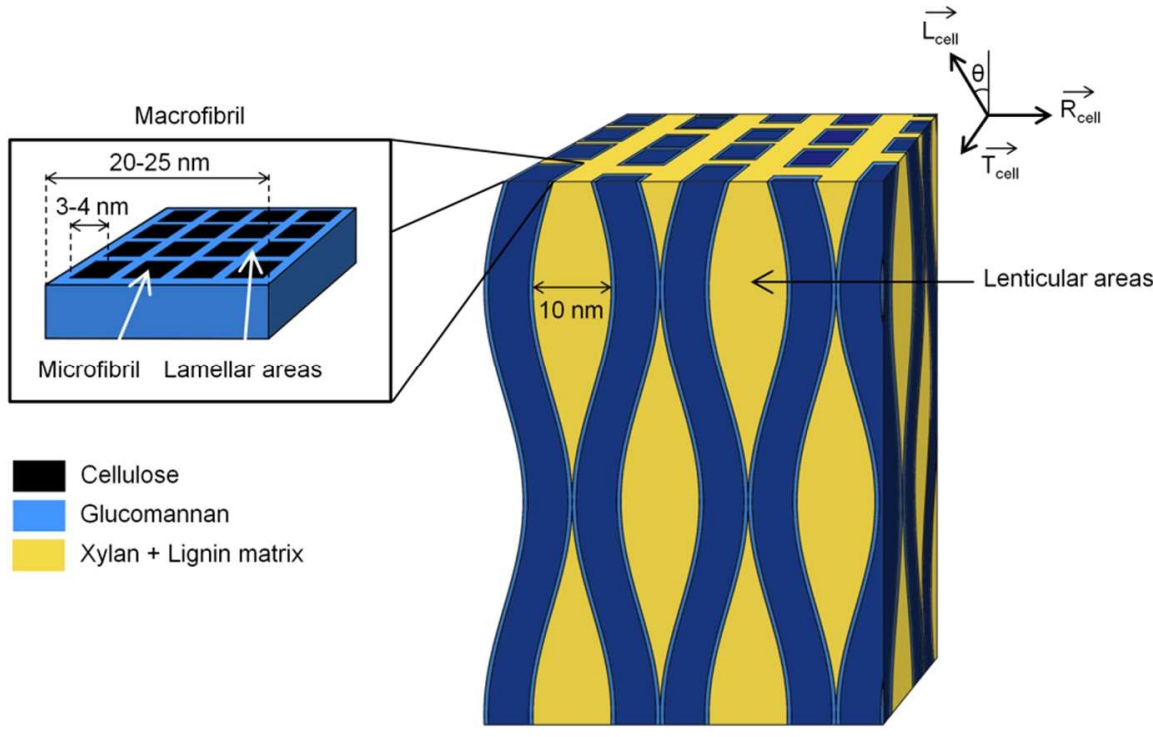

Figure 1 Schematic structure of macrofibrils, inspired by Boyd (1982) and Salmén and 4 Burgert (2009). For clarity, the scheme is neither to scale nor made with regular geometry. It 5 is drawn in the cell baseline $\mathrm{R}_{\text {cell }}, \mathrm{T}_{\text {cell }}, \mathrm{L}_{\text {cell, }}$, with $\theta$ the microfibril angle. 


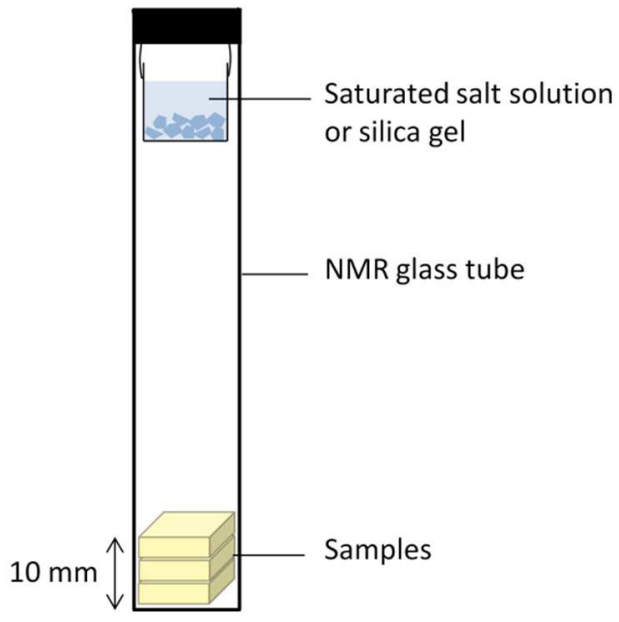

3 Figure 2 NMR device with $\mathrm{RH}$ control.

4 


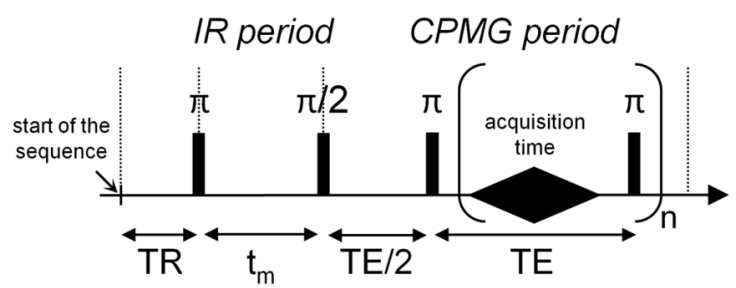

2 Figure 3 Pulse sequence used to acquire the $T_{1}-T_{2}$ correlation spectra.

3 

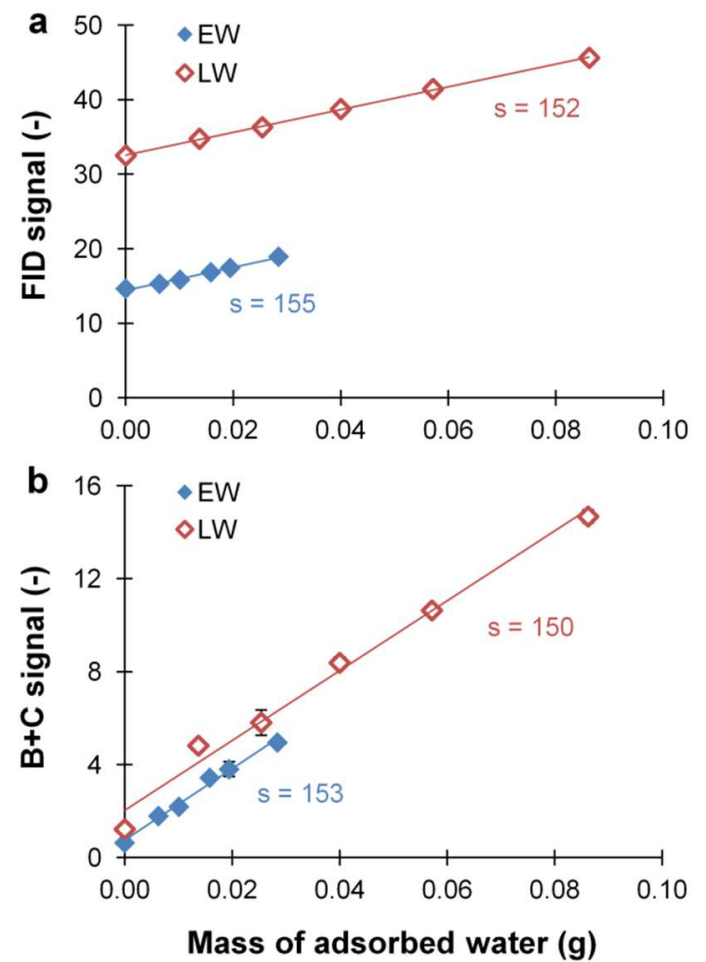

2 Figure 4 (a) FID signal and (b) integrated signal intensity of peaks $B+C\left(T_{1}-T_{2}\right.$ correlation 3 spectra) vs. mass of adsorbed water. $\mathrm{s}$ values correspond to the slopes of a linear trend curve. 

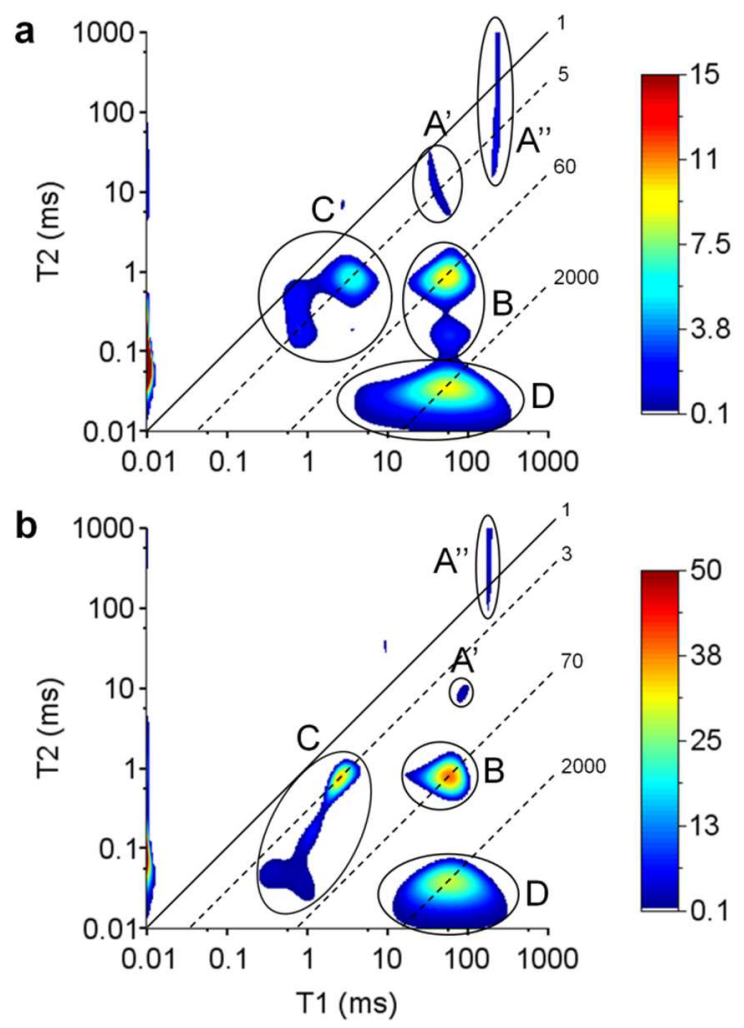

1 Figure $5 \mathrm{~T}_{1}-\mathrm{T}_{2}$ correlation spectra of (a) EW and (b) LW equilibrated at RH 65\%. Diagonal 3 lines correspond to the indicated $\mathrm{T}_{1} / \mathrm{T}_{2}$ values.

4 

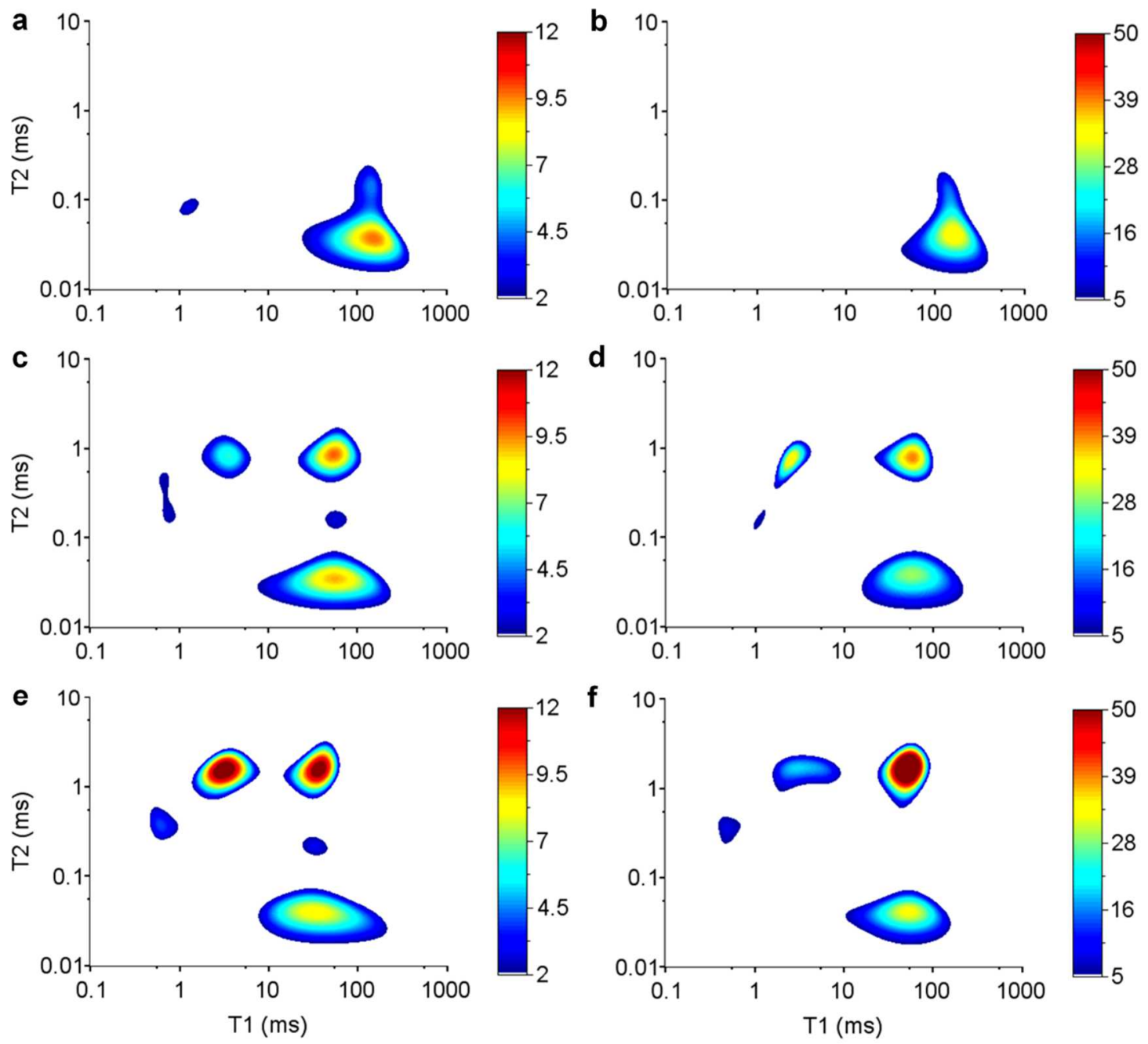

Figure 6 Evolution of the $\mathrm{T}_{1}-\mathrm{T}_{2}$ correlation spectra with RH. (a), (c), (e) EW equilibrated at $2 \%, 65 \%$ and $97 \% \mathrm{RH}$, respectively. (b), (d), (f) LW equilibrated at $2 \%, 65 \%$ and $97 \% \mathrm{RH}$, respectively. 

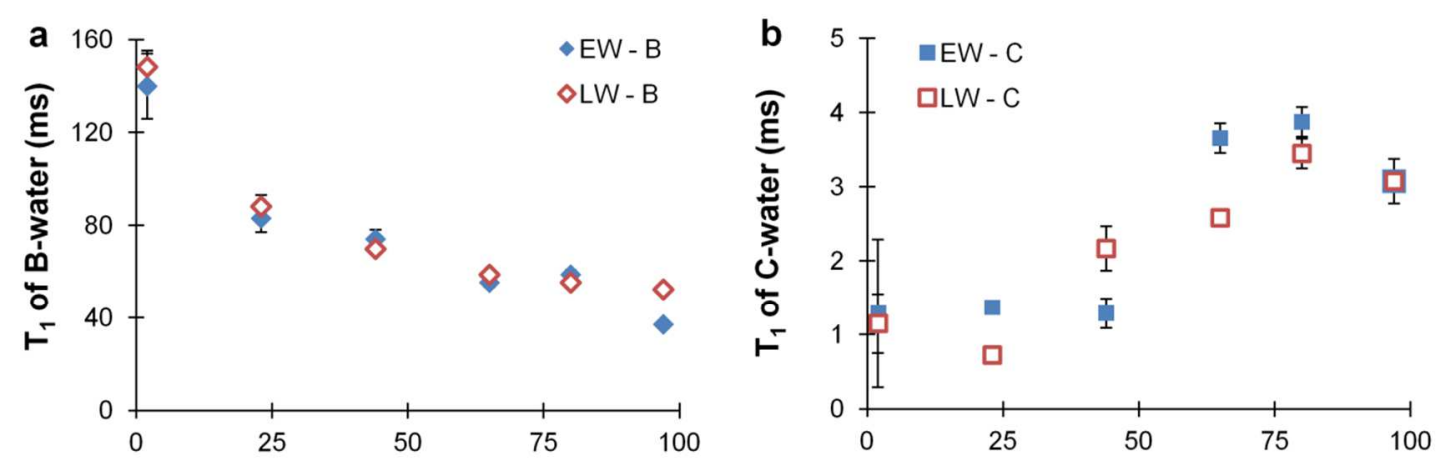

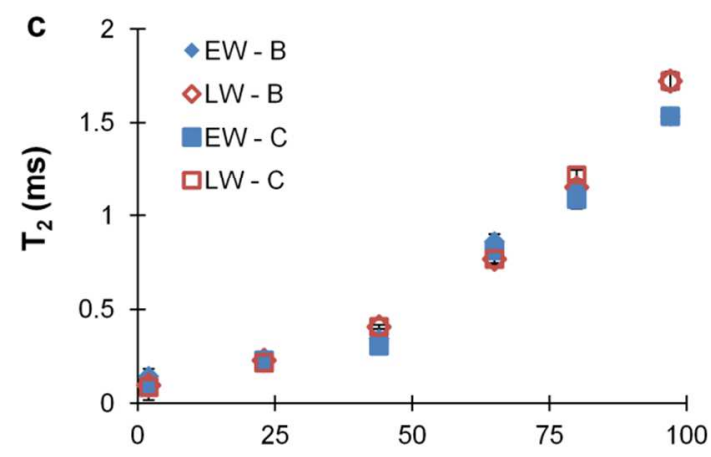

Relative humidity (\%)

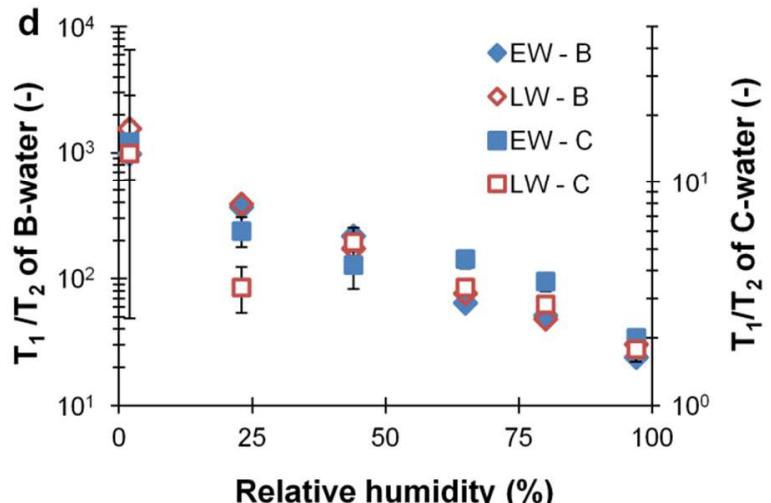

Relative humidity (\%)

2 Figure 7 Evolution with RH of (a) $\mathrm{T}_{1}$ value of peak $\mathrm{B}$ (b) $\mathrm{T}_{1}$ value of peak C (c) $\mathrm{T}_{2}$ values of 3 peaks $B$ and $C$ and $(d) T_{1} / T_{2}$ ratio of peaks $B$ and $C$. 


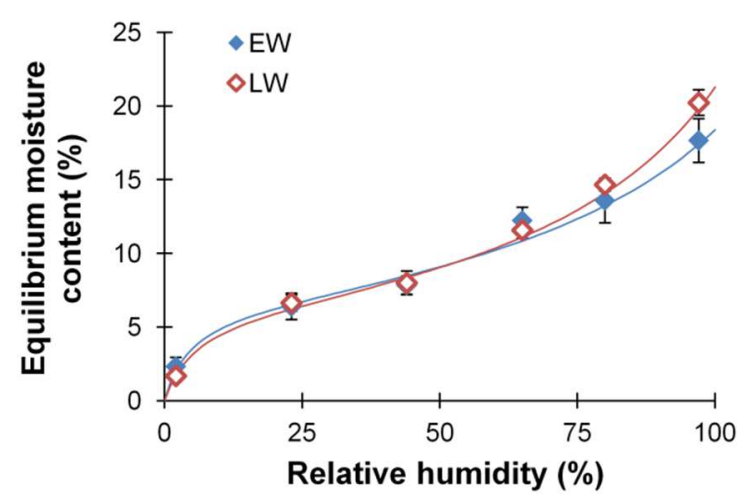

2 Figure 8 Sorption isotherms of EW and LW. Continuous curves: fit to the Dent model. 3 

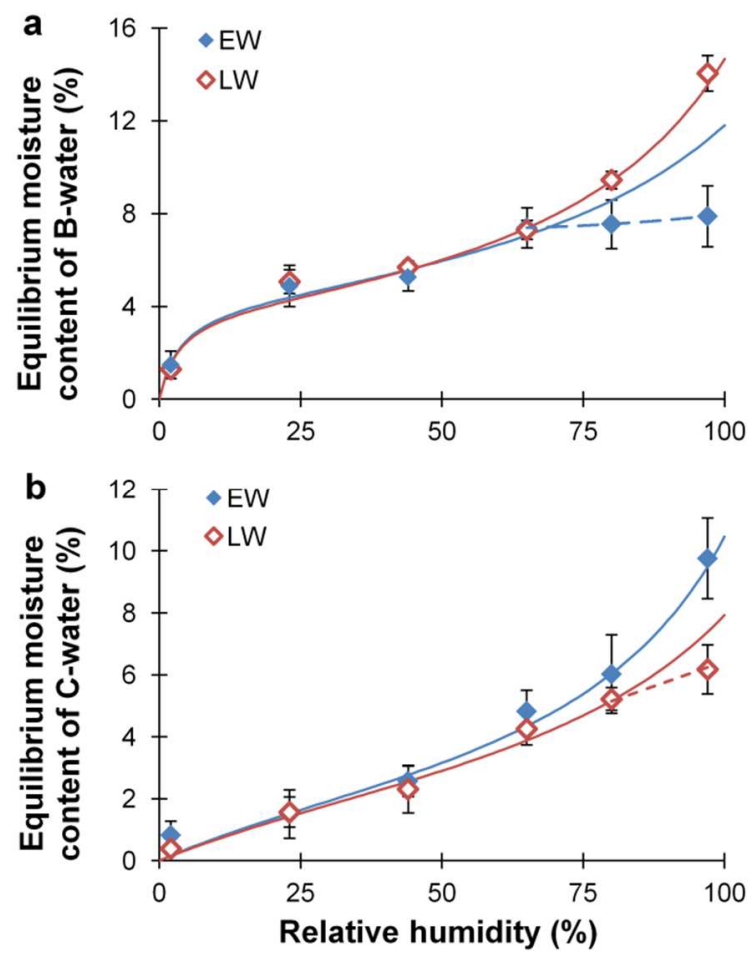

2 Figure 9 Sorption isotherms of (a) B-water and (b) C-water of EW and LW. Continuous 3 curves: fit to the Dent model, applied only up to $65 \% \mathrm{RH}$ for B-water in EW and $80 \% \mathrm{RH}$ for 4 C-water in LW due to the saturation phenomenon. Dashed lines: non-fitted points of these data. 